\title{
Einführung: Energiewende - unter DACH und Fach?
}

\author{
K. Dorfmeister OVE
}

Online publiziert am 4. November 2015

(C) Springer Verlag Wien 2015

CrossMark

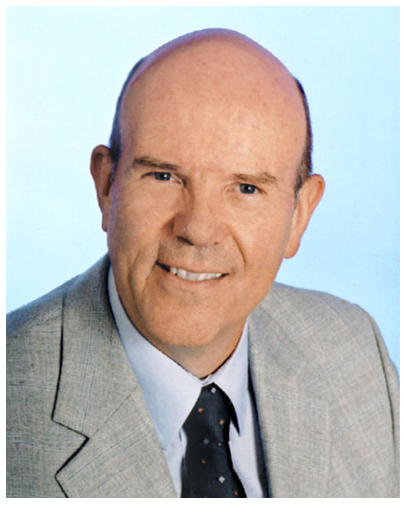

Dipl.-Ing. Dr. Karl Dorfmeister
Seit der Umsetzung der so genannten „Energiewende" in Deutschland ist die Welt der elektrischen Energiewirtschaft nicht mehr so, wie sie früher war. Deutschland ist zurzeit von seinem Ziel, bis 2050 den Anteil der Stromerzeugung aus erneuerbaren Energieträgern auf $80 \%$ zu steigern, zwar noch weit entfernt (derzeit sind es über $30 \%$ ), die Auswirkungen auf den Netzbetrieb sind aber bereits jetzt schon spürbar. Durch das

länderübergreifende Verbundnetz bleiben diese Auswirkungen nicht auf Deutschland allein begrenzt, und so sind alle Transmission System Operators, einschließlich die der Nachbarländer, ständig im Einsatz, die volatilen Stromeinspeisungen im Griff zu haben und für einen sicheren Netzbetrieb zu sorgen.

Vor der "Energiewende" war die Welt der Stromversorgung noch in Ordnung: auf Grund der prognostizierten Stromverbrauchszuwächse wurden sowohl die Kraftwerke (herkömmliche hydraulische und/oder thermische) als auch die sie verbindenden Netze geplant und mehr oder minder zügig errichtet. Es wurde damit den herrschenden physikalischen Gesetzen entsprochen, dass, unter Einhaltung der technischen Netzvorgabe, die Stromerzeugung immer dem Stromverbrauch folgen muss. Diese Kraftwerke gingen ohne Förderungen ans Netz und konnten auch ohne sie betrieben werden. Der "politische Eingriff", die Stromerzeugung zu „demokratisieren" und statt weniger Großkraftwerke viele kleine "regenerative" Stromerzeuger zu fördern, hat jedoch zu einer Umkehr dieser Vorgehensweise geführt. Nicht der Verbrauch bestimmt den Kraftwerkseinsatz, sondern einzig und allein die Verfügbarkeit der Energiequellen (und die ist z. B. bei Wind und Sonne nur begrenzt planbar). Und da in den meisten Fällen (auch aus tariflichen/gesetzlichen Gründen) diese Stromeinspeisungen nur bedingt regelbar sind, war es bis jetzt möglich, und das gar nicht so selten, mit Sondermaßnahmen im Netz das Schlimmste zu vermeiden.

Zumindest in der Branche ist klar, dass es so nicht weitergehen kann. Wird es in Deutschland, Österreich, der Schweiz - oder gar in der gesamten EU - ohne Förderung keinen Kraftwerksbau mehr geben? Eine verordnete "Wiederherstellung früherer Verhältnisse", vor allem unter Berücksichtigung der Schließung der Kernkraftwerke, ist rein systembedingt nicht so schnell umzusetzen, wie es sich die Öffentlichkeit womöglich vorstellt. Auf die in der Regel träge und meist nur anlassbezogen reagierende Politik (Blackout?) zu warten, könnte zu lange dauern, und so sind rechtzeitig entsprechende technische Maßnahmen zu setzen, um das Ärgste zu verhindern.

Welche diese sein können und was schon wie realisiert worden ist, darüber referieren und diskutieren hochkarätige Experten im Rahmen der diesjährigen Gemeinschaftsfachtagung.

Um die Teilnahme an dieser Fachtagung wieder einem großen Kreis von Interessenten zu ermöglichen, wird sie durch die Energie Burgenland AG als Hauptsponsor sowie ABB AG, ALSTOM Austria GmbH, ANDRITZ HYDRO GmbH, Austrian Power Grid AG, Bundesministerium für Verkehr, Innovation und Technologie, EnergieControl Austria, Österreichische Forschungsförderungsgesellschaft $\mathrm{GmbH}$, Pöyry Energy GmbH, Schneider Electric, SIEMENS AG Österreich, Sprecher Automation GmbH, TIWAG-Tiroler Wasserkraft AG, VERBUND Hydro Power GmbH und Wiener Netze GmbH unterstützt, wofür sich die Österreichische Gesellschaft für Energietechnik im OVE auf diesem Wege besonders bedankt.

Karl Dorfmeister Tagungsleiter und Geschäftsführer der OGE
Dorfmeister, Karl, Österreichische Gesellschaft für Energietechnik im OVE, Eschenbachgasse 9, 1010 Wien, Österreich (E-Mail: k.dorfmeister@ove.at) 